\title{
GESTÃO PARA RESULTADOS E AÇÕES DE CONTROLE NA POLÍTICA EDUCACIONAL PAULISTA $^{1}$
}

CILEDA DOS SANTOS SANT'ANNA PERRELLA ${ }^{2}$

ORCID: orcid.org/0000-0002-0885-3396

FELIPE ALENCAR ${ }^{3}$

ORCID: orcid.org/0000-0002-2011-8941

\begin{abstract}
RESUMO: Na perspectiva da internacionalização dos modos de regulação das políticas educacionais e da gestão escolar, o objetivo do artigo é discutir a política educacional paulista no período entre 2007 e 2018. Para tanto, recorreu-se a autores como Akkari (2011), Afonso (2013) e Paro (2012). Apresenta-se uma análise da concepção de gestão na agenda da política educacional da rede estadual de São Paulo, por meio de pesquisa qualitativa sobre fonte documental de programas vigentes desde 2007: Ler e Escrever, Qualidade da Escola e São Paulo Faz Escola, elaborados pela Secretaria de Estado da Educação de São Paulo. As iniciativas foram justificadas com a narrativa de melhoria da qualidade do ensino, circunscrita a resultados em avaliação externa e caracterizam-se por um processo de controle do trabalho pedagógico com a introdução de materiais hiperestruturados em todas as etapas de ensino, elaborados com arranjos público-privados, associação entre metas de índices, desempenho de estudantes em avaliação externa e remuneração por bonificação e papel do professor coordenador como executor do currículo sob moldes técnicos e padronizados. As pretensas melhorias anunciadas evidenciam a gestão para resultados, pautada pelo controle de modo centralizado, em contraposição à previsão da participação ativa da comunidade e à gestão democrática do ensino.
\end{abstract}

Palavras-chave: política educacional, controle do currículo, gestão para resultados, gestão democrática, internacionalização das políticas.

\footnotetext{
${ }^{1}$ Este artigo resulta do projeto de pesquisa Política Educacional na Rede Estadual Paulista (1995 a 2018), financiado pela Fundação de Amparo à Pesquisa do Estado de São Paulo (n. 2018/09983-0) e coordenado por Márcia Aparecida Jacomini.

${ }^{2}$ Universidade de São Paulo (USP) São Paulo, SP, Brasil.

Doutora em Educação pela Faculdade de Educação da Universidade de São Paulo (USP). Professora do curso de Pedagogia da Faculdade Zumbi dos Palmares (FAZP) e pesquisadora da Rede Escola Pública e Universidade (REPU) $<$ www.repu.com.br>.<cileda.perrella@gmail.com>

${ }^{3}$ Universidade Federal de São Paulo (Unifesp). São Paulo, SP, Brasil.

Mestrando em Educação na Faculdade de Educação da USP. Pedagogo da Universidade Federal do ABC (UFABC). Membro da REPU, do Grupo de Pesquisa em Trabalho e Educação da Faculdade de Educação da USP e do Grupo de Estudo e Pesquisa em Política Educacional e Gestão Escolar da Universidade Federal de São Paulo (Unifesp). $<$ alencar.felipe@ufabc.edu.br>
} 


\title{
MANAGEMENT FOR RESULTS AND CONTROL ACTIONS IN THE EDUCATIONAL PUBLIC POLICY OF SÃO PAULO
}

\begin{abstract}
From the perspective of internationalization of the modes of regulation of educational policies and school management, this article aims to discuss São Paulo's state educational public policy between 2007 and 2018, by using authors such as Akkari (2011), Afonso (2013) and Paro (2012). For this purpose, this study presents an analysis of the concept of management in the educational policy agenda of the public school state network of São Paulo, through qualitative research on the documentary source of programs in force since 2007: "Reading and Writing", "Quality of the School" and "São Paulo Makes School", prepared by the São Paulo State Department of Education. The initiatives were justified with the narrative of improving the quality of teaching, limited to results in external evaluation and are characterized by a process of control of pedagogical work with the introduction of hyper-structured materials in all stages of teaching, prepared with public-private arrangements, the association between educational index goals, student performance in external evaluation and bonus remuneration and the role of coordinating teacher as an executor of the curriculum under technical and standardized molds. The announced improvements alleged evidence the management for results public policy, guided by a centralized control, in contrast to the prediction of active community participation and democratic management of education.
\end{abstract}

Keywords: education public policy, curriculum control, management for results, democratic management, internationalization of policies.

\section{GESTIÓN PARA RESULTADOS Y ACCIONES DE CONTROL EN LA POLÍTICA EDUCATIVA PAULISTA}

RESÚMEN: En la perspectiva de la internacionalización de los modos de regulación de las políticas educativas y la gestión escolar, el objetivo del artículo es discutir la política educativa de São Paulo en el período comprendido entre 2007 y 2018, utilizando autores como Akkari (2011), Afonso (2013) y Paro (2012). Para este propósito, se presenta un análisis del concepto de gestión en la agenda de política educativa de la red estatal de São Paulo, a través de una investigación cualitativa sobre las fuentes documentales de los programas vigentes desde 2007: "Lectura y escritura", "Calidad de la escuela" y "São Paulo hace escuela", preparado por el Departamento de Educación del Estado de São Paulo. Las iniciativas se justificaron con la narrativa de mejorar la calidad de la enseñanza, limitada a los resultados de la evaluación externa y se caracterizan por un proceso de control del trabajo pedagógico con la introducción de materiales hiperestructurados en todas las etapas de la enseñanza, preparados con arreglos público-privados, asociación entre objetivos de índice de educación, desempeño del estudiante en evaluación externa y remuneración adicional y papel del maestro coordinador como ejecutor del currículo escolar bajo moldes técnicos y estandarizados. Las supuestas mejoras anunciadas muestran la gestión para resultados, basada por el control de forma centralizada, en lugar del pronóstico de la participación activa de la comunidad y de la gestión democrática de la enseñanza.

Palabras clave: política educativa, control curricular, gestión para resultados, gestión democrática, internacionalización de políticas. 


\section{INTRODUÇÃO}

As duas décadas dos anos 2000 evidenciam o avanço global de políticas educacionais alinhadas ao ideário neoliberal já enfatizadas na década de 1990, que pregam a diminuição do papel do Estado com as políticas sociais, o ajuste fiscal, a economia regulada pelo mercado, a gestão para resultados, os desafios a partir dos avanços tecnológicos com reflexos no campo educacional. Apropriando-se do discurso da democracia, da garantia de direitos, da diminuição das desigualdades, essas políticas apresentam estratégias que, em grande medida, via mecanismos de controle, aniquilam e/ou anulam direitos, como aquele que garante a participação da população nas tomadas de decisões sobre o bem público.

No Brasil, a muito jovem gestão democrática do ensino, fruto de lutas sociais por direitos, entre eles o da participação nas instâncias decisórias, consagrada na Constituição Federal de 1988 (CF/88), na Lei de Diretrizes e Bases da Educação Nacional de 1996 (LDB/96) reafirmada no Plano Nacional de Educação de 2001 (PNE), bem como na meta 19 do PNE de 2014 (BRASIL, 1988; 1996; 2001; 2014), já contando nos anos 2000 com algumas experiências interessantes registradas em escolas e em redes de ensino, é colocada em xeque, diante de encaminhamentos pautados por agentes externos à educação que, autorizados pelas administrações, passam a ditar as formas e conteúdos das políticas educacionais.

$\mathrm{Na}$ perspectiva da internacionalização de modelos de regulação das políticas educacionais, segundo Abdeljalil Akkari (2011), nos anos 2000 evidenciou-se uma crescente pressão para a descentralização do ensino com aumento da participação do setor privado na elaboração de agendas e formulação de políticas para a educação básica. São exemplos expressivos de políticas que se internacionalizaram: a redução de gastos com ensino e a pressão sobre professores, que são obrigados a prestar contas de suas ações pedagógicas pela aferição de resultados. São propostas desenvolvidas em diferentes países, com políticas atreladas a governos de distintos matizes político-ideológicos. Em países democráticos, elas estão muito presentes no debate eleitoral, sendo constantemente avaliadas.

Num movimento global, políticas adotadas em um país rapidamente são "apropriadas pelas elites políticas e poderosos grupos de interesse em outros países” (AKKARI, 2011, p. 13), enraizando-se de formas diferenciadas nos sistemas nacionais. Grupos diversos, exteriores à escola, como setores políticos, sociais, industriais, financeiros, por exemplo, passam a pautar a educação. No entanto, a história de cada país, região e localidade faz a sua interpretação, contando com as reflexões de movimentos sociais, sindicatos entre outros. Tensões entre o global, o nacional e o local são evidenciadas e, nessa perspectiva, Akkari (2011, p. 17) afirma que "as políticas nacionais de educação não podem mais ser concebidas e implementadas sem considerar os debates internacionais".

$\mathrm{Na}$ discussão sobre descentralização, privatização, globalização, o autor trata da accountability como a obrigação de apresentar resultados ou prestação de contas, relacionando-a com a boa governança (AKKARI, 2011), e sugere sua relação com ações previstas para atingir metas propostas na política educacional. Assim, seguindo a lógica de internacionalização das políticas educacionais, tem sido comum governos federal e estaduais e municipais apresentarem suas proposições. Do ponto de vista da regulação das políticas, a adoção de estratégias de controle da gestão possui reflexos diretos no trabalho na escola e podem surgir como marcas de governos.

Exemplo disso ocorreu no início de setembro de 2019, quando o governador do Estado de São Paulo João Dória Júnior, do Partido da Social Democracia Brasileira (PSDB), comunicou em sua conta do Twitter sobre "um erro inaceitável" contido nos Cadernos do Aluno, do programa São Paulo Faz Escola, destinados a estudantes do $8^{\circ}$ ano do ensino fundamental (EF), e ordenou que o secretário de educação Rossieli Soares da Silva os recolhesse de modo imediato, alegando que tal erro se referia à "apologia da ideologia de gênero". Em seguida, a Secretaria de Estado da Educação (Seduc) instituiu um Grupo de Trabalho (GT) para analisar e revisar os materiais (SÃO PAULO, 2019) e, em poucas horas, a grande maioria dos Cadernos em posse de estudantes haviam sido recolhidos.

Após alguns dias desse grave ato de censura e controle do conteúdo ensinado nas escolas sem qualquer tipo de justificativa legal e processo de comunicação formal ou diálogo, o Governo do Estado de São Paulo foi obrigado a devolver os materiais por força de Ação Judicial movida por um 
grupo de professores-pesquisadores e advogados. ${ }^{4}$ Em carta a diretoras e diretores da rede estadual paulista, o referido grupo considera:

Tal fato diz muito sobre o atual estado das escolas em São Paulo, as dificuldades de gestão que enfrentam, o tratamento que recebem das autoridades políticas e da Secretaria Estadual de Educação - SEDUC e a visão destes sobre o papel de diretoras e diretores na implementação das políticas públicas de educação (REDE ESCOLA PÚBLICA E UNIVERSIDADE, 2019, p. $1)$.

Instigados por essa ação, apresenta-se a seguinte questão: a política educacional paulista já não havia pavimentado uma via para que houvesse tal controle sobre o currículo e a gestão das escolas?

Neste artigo, o objetivo é discutir a política educacional paulista no período entre 2007 e 2018 a partir de pesquisa qualitativa com análise documental (CELLARD, 2008). Frente à perspectiva da internacionalização das políticas educacionais, este texto apresenta uma análise da concepção de gestão na agenda da política educacional da rede estadual paulista, com base nos projetos e programas Ler e escrever, Qualidade da Escola (que condensa Saresp ${ }^{5}$ e Idesp ${ }^{6}$ ) e São Paulo Faz Escola vigentes desde 2007, na gestão governamental em que foram implementados. Esta abordagem permite que sejam realizadas pesquisas que se dediquem sobre relações entre as administrações que se sucederam, dada a permanência do mesmo partido no governo desde 1995 - PSDB.

O texto está organizado com as seguintes discussões: o controle do trabalho pedagógico com base numa narrativa da qualidade do ensino; uma análise dos referidos programas na agenda da política educacional paulista; a legitimação de tais ações referenciadas na internacionalização dos modos de regulação. Finaliza-se com uma síntese da crítica à não relevância da gestão democrática nas políticas educacionais do Estado de São Paulo.

\section{CONTROLE EM NOME DA MELHORIA DA QUALIDADE DO ENSINO}

A melhoria da qualidade do ensino nas escolas da rede estadual foi anunciada como uma prioridade da agenda para a educação na gestão do ex-governador José Serra (PSDB) em 2007, ${ }^{7}$ balizado pelos resultados aferidos no censo escolar e em avaliações externas e construiu uma narrativa de que o desempenho do sistema escolar estadual era insuficiente (SÃO PAULO, 2007a).

Foram privilegiadas as avaliações externas valendo-se da criação de índices e metas para, supostamente, mobilizar as escolas a melhorarem seus resultados. Consideramos neste texto que a gestão do currículo se constituiu de um conjunto de ações que conferiu centralidade ao controle do trabalho pedagógico realizado nas escolas da rede de ensino, com base nos três volumes do Caderno do gestor: gestão do currículo na escola (SÃO PAULO, 2008d, 2008e, 2009c) elaborados pela Seduc.

Políticas ditas de avaliação constituíram-se num duplo investimento na rede estadual: levantar informações para a formulação de programas e projetos, servindo para a definição de prioridades do governo e sua respectiva focalização, induzir mudanças e consolidar reformas que já estavam previamente estruturadas para o ensino público.

Com a implantação, em 1995, do Sistema de Avaliação do Rendimento Escolar de São Paulo (Saresp), ${ }^{8}$ considerado como antessala de políticas educacionais de metas e centralização do currículo, a principal conclusão do governo foi realizar maior controle sobre o trabalho pedagógico por meio de metas do Índice de Desenvolvimento da Educação de São Paulo (Idesp) e do programa São Paulo Faz

\footnotetext{
${ }_{4}$ Trata-se da Ação Popular movida por um conjunto de professores vinculados à Rede Escola Pública e Universidade (REPU), com apoio jurídico do Coletivo de Advocacia em Direitos Humanos (CADHu). A referida Ação Popular está disponível em <www.repu.com.br/acao-popular-apostilas >. Acesso em 17 mai. 2019.

${ }^{5}$ Sistema de Avaliação do Rendimento Escolar de São Paulo (Saresp).

${ }^{6}$ Índice de Desenvolvimento da Educação de São Paulo (Idesp).

${ }^{7}$ Os pontos da agenda podem ser consultados em <http://www.saopaulo.sp.gov.br/spnoticias/ultimas-noticias/sp-lancaagenda-para-educacao-publica/>. Acesso em 24 de maio de 2019.

${ }_{8}$ Trata-se de uma aferição do rendimento escolar por meio de uma prova aplicada a estudantes de $5^{\circ}$ e $9^{\circ}$ anos do EF e $1^{\circ}$ e $3^{\circ}$ ano do ensino médio, especificamente sobre conteúdos de língua portuguesa e matemática. 
Escola, uma proposta curricular elaborada de modo centralizado. Essas políticas induziram uma certa longevidade, pelo fato de a primeira prever duração até 2030 e, em função deste índice, a segunda compor um aparato técnico da Seduc, que se traduziu na política de gestão para resultados, pretensamente perene.

Esse conjunto de políticas deu continuidade às ações de avaliação externa adotadas pelo governo federal nas gestões de Fernando Henrique Cardoso (1995-2002) e de Luís Inácio Lula da Silva (2003-2006 e 2007-2010). Em 2007, de modo a monitorar as metas e ações do Plano de Desenvolvimento da Educação (PDE), ${ }^{9}$ foi criado o Índice de Desenvolvimento da Educação Básica (Ideb), ainda em vigência, obtido a partir da agregação da taxa média da aprovação, captada pelo Censo Escolar, e a pontuação média da Prova Brasil (BRASIL, 2007a).

Com o Ideb em nível nacional, a intenção de implantar o Idesp teve em vista a possibilidade de comparação internacional dos dados educacionais da rede estadual, em detrimento de comparação consigo mesma, que considerasse seu tempo histórico e o contexto sócio-político no qual a rede estava inserida.

Contudo, o diferencial do governo estadual paulista consistiu na unidade entre política de metas quantitativas e controle por meio do currículo sob o eixo da gestão para resultados, representada na expressão: gestão para resultados = avaliações externas + metas + currículo centralizado.

Com foco nos resultados do Saresp e seguindo a lógica de ações para "a boa governança" (AKKARI, 2011), o currículo passou a ser centralizado via material didático para as escolas. Textos e exercícios passaram a ser produzidos pela Seduc, para serem utilizados em sala de aula, tendo como conteúdo base o que seria cobrado no Saresp. ${ }^{10}$

A política educacional paulista firmou forte ligação da gestão do currículo com as avaliações externas pois estas interferem, assim como o material didático distribuído às escolas, no conteúdo a ser ensinado e nos espaços de trabalho coletivo entre docentes e equipe gestora. Com a consolidação da proposta curricular, no ano de 2009 a taxa de participação de estudantes na prova do Saresp foi recorde na história da aplicação da prova. ${ }^{11}$ Os horários de trabalho pedagógico coletivo também passaram a ser pautados em orientações sobre o uso de apostilas e na centralidade em aplicá-las (BOIM, 2010).

\section{IMPLANTAÇÃO DE POLÍTICAS PAUTADAS NA GESTÃO DO CONTROLE PEDAGÓGICO}

$\mathrm{Na}$ perspectiva de marcar a sua estratégia de gestão do currículo aliada à gestão para resultados, desde 2007 o governo paulista adota iniciativas articuladas e ditas inovadoras: o programa Ler e Escrever articulado ao Bolsa Escola Pública e Universidade; o Programa Qualidade da Escola e Idesp e o Programa São Paulo Faz Escola, propostas que serão tratadas na sequência.

\section{Ler e Escrever e Bolsa Escola Pública e Universidade na gestão para resultados}

O Programa Ler e Escrever, lançado em 2007, contém um material didático, Cadernos para o educador, que oferece um caminho a ser trilhado pelo professor alfabetizador, tendo em vista a apresentação de resultados, focado em orientações sobre as atividades, passo a passo. Seu conteúdo se revela como aplicável para qualquer criança, independentemente de seu contexto social, econômico, cultural. Por exemplo: para leitura e escrita são propostos trabalhos com contos tradicionais, parlendas, entre outros gêneros literários. Questões de classe, gênero, raça e etnia, entre outras presentes no cotidiano das crianças, são invisibilizadas. Caso a escola tenha tais reflexões registradas no seu Projeto

\footnotetext{
${ }^{9} \mathrm{O}$ PDE foi adotado pelo governo de Luís Inácio Lula da Silva, tendo Fernando Haddad como ministro da educação.

${ }^{10} \mathrm{Em}$ 2008, professores da rede estadual fizeram greve que durou 22 dias e, em 2009, foram exibidos na chamada grande mídia erros em materiais didáticos distribuídos às escolas. Conforme notícia em $\mathrm{O}$ Estado de S. Paulo, disponível em $<$ educacao.estadao.com.br/noticias/geral,livro-traz-dois-paraguais-e-exclui-equador-nas-escolas-de-sp,340271>. Acesso em 24 de maio de 2019.

${ }^{11}$ Conforme notícia disponível em <https://www.educacao.sp.gov.br/noticias/saresp-tem-a-maior-adesao-de-toda-a-suahistoria/>. Acesso em 20/11/2019.
} 
Político Pedagógico, o uso literal do Ler e Escrever poderá trazer impasses para o professor e, assim, as intencionalidades expressas no programa revelam suas limitações.

Pretensamente ligado à melhoria dos dados da prova do Saresp aplicada em 2005, o Ler e Escrever é um programa de intervenção pedagógica na sala de aula, junto ao professor e estudantes e de intervenção na gestão, envolvendo supervisão, direção e coordenação pedagógica, no conjunto da escola. Com origem na Prefeitura do Município de São Paulo e, considerada como uma experiência exitosa, foi implantado na rede estadual, por meio da Resolução 22/2007 (SÃO PAULO, 2007b), que instituiu um GT coordenado por Iara Glória Areias Prado, ${ }^{12}$ à época secretária-adjunta e também participante da Fundação para o Desenvolvimento da Educação (FDE).

O referido GT era responsável por uma série de intervenções junto às equipes da gestão das escolas, incidindo, sobretudo, em ações de formação para assistentes técnico-pedagógicos, supervisores de ensino, diretores e coordenadores pedagógicos das escolas envolvidas.

Apesar deste autodeclarado empenho, a formação para a cidadania, a convivência social, a tomada de decisões coletivas e individuais, a valorização das diferenças, como pressupostos para uma sociedade democrática, conforme previsto na LDB/1996, são secundarizadas diante do foco voltado apenas ao conteúdo padronizado e não aos sujeitos envolvidos no processo educativo. A expectativa era de que se apresentasse o mais rápido possível o resultado: a/o estudante alfabetizada/o. Os sujeitos eram evidenciados só nas entrelinhas e quanto ao que lhes era imputado como responsabilidade. Docente e estudante, escola e família eram vistos como únicos responsáveis em caso de fracasso do processo da alfabetização. Enquanto o êxito, ao ser identificado, é atribuído à proposta elaborada pelo governo.

Desde sua primeira fase de implantação, sua meta era envolver todas as escolas da capital visando a melhoria da qualidade do ensino, principalmente no tocante à leitura e à escrita, no intento de articulação entre as Secretarias Estadual e Municipal de Educação de São Paulo. Com foco nos quatro anos do ciclo I do EF, às/aos docentes participantes deste programa seriam atribuídas mais 4 horas em sua jornada de trabalho.

Visando metas de longo prazo, o Programa Ler e Escrever declarava como objetivos alfabetizar todos os alunos com idade até oito anos do EF da rede paulista e recuperar a aprendizagem de leitura e escrita de alunas/os de todas as séries do Ciclo I do EF.

Relações entre público e privado também se expressam na articulação entre os programas de resultados de alfabetização da rede estadual paulista.

O programa Bolsa Formação Escola Pública e Universidade foi instituído por meio do Decreto no 51.627/2007 (SÃO PAULO, 2007c), e ainda está em vigência. Destina-se a estudantes dos cursos de graduação de instituições de ensino superior que, sob supervisão de docentes universitários, são incumbidos de atuar nas turmas e no horário de aula da rede estadual de ensino ou em projetos de recuperação e apoio à aprendizagem.

Desenvolvido pela Seduc, diretamente ou por intermédio da FDE, mediante a celebração de convênios com Instituições de Ensino Superior (IES) públicas ou privadas que atuam na formação de docentes para o EF e ensino médio (EM), cujas cláusulas preveem um repasse de recursos da Seduc às IES que firmam o convênio cuja duração é, no mínimo, de 2 anos e pode ampliar-se até 5 anos.

O sistema de cooperação nos programas Bolsa Escola e Universidade e Ler e Escrever prevê a relação público-privado e um instrumento na perspectiva da gestão para resultados adotada pelo governo.

A IES privada, que tem como objetivo central o lucro, nesse tipo de cooperação com o setor público pode ter como contrapartida, por exemplo, a isenção de impostos. Os materiais do programa Ler e Escrever foram elaborados por consultores reconhecidos como diretores de IES particulares, ${ }^{13}$ além disso, o governo do estado permitiu a entrada de agentes privados na implantação das referidas ações de alfabetização e letramento.

\footnotetext{
${ }^{12}$ Iara Glória Areias Prado também compôs o Ministério da Educação (MEC) como secretária de ensino fundamental durante o segundo mandato de Fernando Henrique Cardoso (1999-2002).

13 Por exemplo, Gisela Wajskop, à época diretora do Instituto Singularidades (IES privada), e ex-coordenadora de Educação Infantil do MEC na gestão FHC, escreveu o caderno "Conversa com os pais" do Ler e Escrever. 
Esses programas foram ampliados para as escolas da região metropolitana de São Paulo, a desde 2008, e para cidades do interior, a partir de 2009.

O programa Bolsa Escola Pública Universidade na Alfabetização foi expandido por meio da Resolução no 83/2007, apresentando como metas tanto o apoio à formação inicial de docentes, com atuação de estudantes de licenciatura, como auxiliares de professoras/es em turmas do ciclo de alfabetização persistindo na meta estipulada na primeira fase de implantação do programa: "garantir a aprendizagem da leitura e escrita a todos os alunos" (SÃO PAULO, 2007d).

No que se refere à ampliação do programa Ler e escrever, a Resolução nº 86/2007 considerava urgente "solucionar as dificuldades apresentadas pelos alunos de Ciclo I com relação às competências de ler e escrever, expressas nos resultados do SARESP 2005", sendo necessário "promover a recuperação da aprendizagem de leitura e escrita dos alunos de todas as séries do Ciclo I" e imprescindível "investir na efetiva melhoria da qualidade de ensino nos anos iniciais da escolaridade" (SÂO PAULO, 2007e).

A gestão das escolas estaduais no período passou a ter novas medidas implantadas a partir da ampliação destes projetos e programas, cujo foco inicial era o ciclo de alfabetização, passando a incidir sobre o ciclo 2 do EF e o EM, em 2008.

A primeira medida foi a redefinição do papel de professor coordenador que assumiu, desde então, a coordenação pedagógica da escola em todas as modalidades da educação básica, partilhando a coordenação com a direção da escola e a supervisão de ensino.

A Seduc, na Resolução 88/2007, considerava que "a coordenação pedagógica se constitui em um dos pilares estruturais da atual política de melhoria da qualidade de ensino e que os Professores Coordenadores atuam como implementadores dessa política” (SÃO PAULO, 2007f).

Ao papel do professor coordenador cabia vincular os projetos político-pedagógicos das escolas nas quais trabalhavam às avaliações internas e externas. Tratava-se de um agente que tinha a incumbência de elevar o desempenho escolar estudantil evidenciado nestes instrumentos de avaliação, devendo também intervir na prática de docentes das escolas para diversificar as propostas de trabalho tendo como meta a superação de dificuldades detectadas junto às/aos alunos e com vistas à eficácia de seu trabalho (SÃO PAULO, 2007f).

De um lado, o professor coordenador tinha o desafio de fomentar o ensino como processo educativo, de outro, devia atuar no processo pautado para resultado, evidenciando seu papel de gestor controlador do currículo na escola, que, segundo a retórica do programa, deve ter como objetivo melhorar resultados quantitativos no Saresp.

\section{Programa Qualidade da Escola (PQE)}

O Programa Qualidade da Escola introduziu pari passu à centralização do currículo a mudança na natureza das escolas estaduais tornando o Saresp a principal forma de medir a qualidade escolar.

Temas caros como evasão, repetência e aprendizagem de estudantes passaram a ser tratados como um empreendimento profissional numérico conferindo bônus salarial. O esforço de envolver as comunidades escolares na melhoria da qualidade da educação também se transformou em estratégia de controle e de contabilidade, na qual o modus operandi é seguir regras e mensurar, depois punir ou recompensar.

Em contraposição à participação da comunidade na construção do currículo da escola, como expressão de sua gestão democrática, a partir do Programa Qualidade da Escola (PQE) os demais programas e projetos da Seduc assumiram uma associação mais evidente com a política de gestão pautada pelo controle. Instituído pela Resolução n ${ }^{\circ}$ 74/2008 (SÃO PAULO, 2008a), o PQE introduziu na gestão das escolas estaduais o Idesp, como mais um indicador da qualidade do ensino e, tal qual o Ideb, é calculado com base nos dados de fluxo escolar, índices de promoção e no desempenho dos estudantes nas avaliações externas. A partir do Idesp são fixadas metas anualmente, previstas de 2008 até 2030, a serem atingidas em cada escola da rede estadual paulista.

Segundo a Resolução n ${ }^{\circ} 74 / 2008$, o PQE e o Idesp possuem a intenção de avaliar a qualidade das escolas estaduais no EF e EM, fixar metas para orientar a equipe de gestão na tomada de decisões, 
de modo a direcionar as escolas para a melhoria dos serviços educacionais e subsidiar ações para a promoção da melhoria da qualidade e da equidade nas escolas da rede estadual (SÃO PAULO, 2008a).

A Seduc afirmou que, para atingir o objetivo de "promover a melhoria da qualidade e a equidade do sistema de ensino na rede estadual paulista", a tarefa era avaliar "anualmente cada escola [...] de maneira objetiva, a fim de acompanhar a qualidade do serviço educacional prestado" e propor "metas para o aprimoramento da qualidade do ensino que oferecem" (SÃO PAULO, 2009a, p. 1).

Segundo a Seduc, ao avaliar a qualidade da escola, "uma boa escola é aquela em que a maior parte dos alunos apreende as competências e habilidades requeridas para a sua série, num período de tempo ideal - o ano letivo" (SÃO PAULO, 2009a, p. 1), ressaltando que o desempenho de estudantes no Saresp e o fluxo escolar constituem-se critérios da qualidade do ensino.

O papel da supervisão de ensino foi adequado à política de gestão para resultados, como se explicita na Resolução n 97/2009: "ação supervisora na implementação e acompanhamento das políticas, diretrizes e metas da educação"; salientando que era necessário "racionalizar os critérios utilizados na fixação de setores de trabalho, à vista dos índices de desenvolvimento da educação, obtidos pelo Programa Qualidade da Escola" e considerando que as metas da educação visavam à melhoria da qualidade do ensino nas escolas estaduais (SÃO PAULO, 2009b, grifo nosso).

$\mathrm{Na}$ hierarquia de poderes da Secretaria Estadual de Educação, o supervisor de ensino é Membro de Equipe de Supervisão de Instância Regional, diretamente subordinado à Diretoria de Ensino. Porém, o supervisor de ensino era o responsável pelos erros e falhas que se refletissem nos resultados do Saresp, caso não tivessem sido orientados adequadamente a serem superados.

A supervisão de ensino também era mobilizada a orientar as equipes de gestão das escolas estaduais a se instrumentalizarem tanto para ajustes em relação a diversas dimensões do aparato escolar tendo em vista que as escolas atingissem as metas de Idesp.

Parte desse enquadramento foi coroado com a Lei Complementar $n^{\circ}$ 1078/2008 que instituiu a bonificação por resultados, cujo bônus é um acréscimo na folha de pagamento sem vinculação aos vencimentos do/a servidor/a e não incide como fator previdenciário e de assistência médica, pago em proporção direta às metas atingidas na escola, no período de um ano, e ainda está em vigência no período de escrita deste artigo (SÃO PAULO, 2008b). Mas seu pagamento depende de dotação orçamentária do Governo do Estado e em casos nos quais a escola supera a meta estabelecida pela Seduc, o bônus é pago em duas parcelas (SÃO PAULO, 2008b, art. $9^{\circ}$ ).

A partir do PQE, a Seduc implantou ações de impacto sobre o currículo escolar, o papel das equipes de gestão da rede estadual e a política salarial do quadro do magistério e da gestão escolar.

\section{São Paulo Faz Escola: centralização do currículo e professor coordenador como gestor controlador}

O programa São Paulo Faz Escola - Proposta Curricular foi implantado pela Seduc no dia seguinte ao lançamento do PQE, como consequência deste projeto. Com isto, a gestão do currículo ganhou um encaminhamento específico, buscando articular as ações na política de gestão para resultados com o lançamento do Caderno do Gestor, focando sujeitos executores da proposta e evidenciando forte marca de controle das ações pedagógicas da escola.

A proposta curricular teve seus materiais elaborados pela Coordenadoria de Estudos e Normas Pedagógicas (CENP) e uma equipe de assessoria pedagógica constituída de docentes universitários, ${ }^{14}$ incluindo alguns da USP. Os materiais da proposta foram intitulados Cadernos e, no caso de estudantes, constituía-se de um caderno de atividades, logo batizado de Apostila.

Com objetivo de "estabelecer referenciais comuns que atendam ao princípio de garantia de padrão de qualidade" e "subsidiar as equipes escolares com diretrizes e orientações curriculares comuns que garantam ao aluno acesso aos conteúdos básicos, saberes e competências essenciais" (SÃO PAULO, 2008c), com efeito sobre todas as unidades curriculares e linguagens trabalhadas com os estudantes da rede, a política previu a complementação de "um conjunto de documentos, com orientações didáticas e

\footnotetext{
${ }^{14}$ A coordenação geral era de Maria Inês Fini e a concepção do material foi de Guiomar Namo de Mello, Lino de Macedo, Luís Carlos de Menezes, Maria Inês Fini e Ruy Berger.

Educação em Revista|Belo Horizonte|v.38|e25020|2022
} 
expectativas de aprendizagem, distribuídas por níveis de ensino, anos e séries" e "o apoio de materiais impressos, recursos tecnológicos e com ações de capacitação e monitoramento" (SÃO PAULO, 2008c, art. $2^{\circ}$ e $\left.3^{\circ}\right)$.

O Caderno do Gestor teve três volumes lançados. No início dos volumes 1, 2 e 3, a secretária de educação teceu críticas indiretas às gestões anteriores do PSDB, ao afirmar, na "Carta aos gestores", que a proposta curricular apresentada em sua gestão se trata de "um 'divisor de águas' para a educação paulista" (SÃO PAULO, 2008d, p. 3). E complementou, ainda, afirmando que tal proposta era organizada e integrada, ora dando a entender que o currículo da rede paulista se encontrava, então, em condições opostas nas gestões anteriores. Tal crítica, feita de maneira indireta, não aparece em outras redações do Caderno do gestor, mas é significativa, uma vez que o governo em questão é o próprio PSDB, partido da ex-secretária Maria Helena de Castro, que governa o estado de São Paulo desde 1995, mesmo que se valendo de coalizões diversas. Ou seja, mesmo num governo que se apresenta como de continuidade, há críticas e discordâncias quanto aos encaminhamentos até então adotados, propondo uma guinada a partir da nova proposta.

A "Carta aos gestores" parece indicar a compreensão de ser endereçada ao/à diretor/a da escola. Contudo, na apresentação dos Cadernos assinada por Maria Inês Fini, Coordenadora Geral da Proposta Curricular, afirma-se que o conteúdo do Caderno foi "especialmente produzido para o Professor Coordenador" e é possível perceber a explícita divisão entre quem pensa e quem deve executar as propostas, dicotomia há muito questionável. A exemplo do anunciado no volume 1, "1. O que se espera do professor coordenador" (SÃO PAULO, 2008d, p. 7) que ressalta o novo perfil gestor desse profissional, asseverando que ele "deve ter o domínio amplo de uma competência comunicacional, uma vez a implantação efetiva dos significados da Proposta Curricular, que ele irá representar, prevê a adesão de outros agentes da escola [...]" (idem).

O volume 1 do Caderno traz prescrições de qual deve ser a postura do Professor Coordenador, listando o que ele deve "evitar" e o que deve "assumir" (SÃO PAULO, 2008d, p. 8) e as "competências" que deve ter (idem, p. 9). Na perspectiva a Seduc pensa e o Professor Coordenador executa, o Caderno volume 1 traz, também, o que chama de "Primeira Ação Pública do Professor Coordenador", que se trata da divulgação da Proposta Curricular. Para tanto, apresenta uma agenda cronometrada a ser seguida, que finaliza com o seguinte lembrete: "Terminando esse processo, faça um relatório dessa primeira etapa e organize os dados coletados. Posteriormente, eles serão encaminhados para diferentes públicos. A próxima agenda é a organização das HTPCs" (SÃO PAULO, 2008d, p. 44).

O professor coordenador, até então entendido como aquele profissional que atuava com seus pares na perspectiva formativa, estabelecendo diálogo, por vezes sendo o interlocutor de demandas por eles apresentadas, tem seu status elevado ao de gestor, a partir de um material voltado particularmente a moldar sua atuação.

A Seduc atribui ao professor coordenador um papel político na condução "coercitiva" da proposta que, mais diretamente, se esperava da figura da direção da escola, ou, em uma compreensão ampliada, da equipe gestora (diretor/a, vice-diretor/a e professor/a coordenador/a).

Figura estratégica para o avanço do programa Ler e Escrever, das metas de Idesp e da implantação da proposta curricular, a ênfase colocada na figura do professor coordenador parece ter objetivos ocultos de deslocar o eixo de muitos ranços antes direcionados à direção para o professor coordenador.

Por um lado, ficando a possibilidade de firmar outro tipo de relação com o/a diretor/a da escola mais caracterizada pela cumplicidade do que pela obediência, por outro, com a elevação do status do Professor Coordenador ao de gestor, como explícito no Caderno. Tem-se um profissional tarefeiro, cumpridor da demanda a ele apresentada sem grandes espaços para questionamento.

Desse modo, proporciona-se a diferenciação do Professor Coordenador, tanto de seus pares quanto dos demais integrantes da chamada equipe gestora (diretor/a e vice-diretor/a), recaindo sobre si a obrigatoriedade de intervenção junto aos/às professores/as, podendo tornar inócuo quaisquer questionamentos à proposta. Esta relação explicita hierarquização, verticalidade e obediência, com vistas ao êxito do programa. Verifica-se, assim, que o princípio da gestão democrática, que prevê a participação da comunidade e de docentes na elaboração do Projeto Político Pedagógico da Escola, é completamente 
ignorado, uma vez que não prevê que a escola tenha autonomia para elaborar com a comunidade escolar sua própria proposta. Esta deverá ser recebida, intermediada e transferida às/aos docentes pelo Professor Coordenador. resultados:

No volume 1 do Caderno do Gestor ${ }^{15}$ fica explícita a perspectiva técnica de gestão para

Gestão é entendida aqui como o esforço consciente dos sujeitos responsáveis pela escola para gerar mudanças, a partir da tomada de decisões sobre o planejamento, sua aplicação e avaliação. Isso exige competência técnica, participação responsável e compromisso com os resultados educacionais efetivos e significativos. (SÃO PAULO, 2008d, p. 7)

Considerando o professor coordenador como um dos pilares na implantação da proposta curricular, o Caderno do Gestor informava que a expectativa quanto ao trabalho do professor coordenador era de que ele fosse "capaz de definir e articular múltiplas ações voltadas para a qualidade do ensino e de seus resultados na aprendizagem dos alunos" (SÃO PAULO, 2008d, p. 7). Declarava esperar que tal profissional atuasse por meio do consenso e também rebatesse as críticas da equipe de trabalhadores da educação à proposta curricular, que associava os Cadernos à instrumentalização da avaliação de melhoria dos resultados da gestão e do ensino:

O ceticismo dos agentes ao receberem a Proposta deve ser considerado como um argumento real. $[\ldots]$

O Professor Coordenador, para rebater esse argumento, deve estar informado sobre as ações "práticas" da Secretaria, e usar essa informação para convencer os agentes de que a Proposta Curricular é, antes de tudo, uma Proposta Política que apoia os movimentos inovadores escolares [...]. Para isso, lança mão de pesquisas educacionais permanentes sobre a evolução e avaliação dos critérios de qualidade da gestão e do ensino e de seus resultados. (SÃO PAULO, 2008d, p. 8-9)

Já o volume 2 do Caderno do Gestor focalizava os resultados do desempenho dos estudantes no Saresp aplicado em 2008 e na responsabilidade do professor coordenador de conversão dos resultados alcançados, nas suas respectivas escolas, tendo em vista a gestão focada na melhoria do desempenho:

Por isso, o objetivo principal deste volume é ajudar esse professor na organização das discussões coletivas, dando-lhe uma noção geral dos resultados, para que possa transformá-los em propostas de ação voltadas à melhoria do processo de ensino-aprendizagem. (SÃO PAULO, 2009c, p. 7)

E o volume 3 do Caderno do Gestor tem foco na construção do planejamento pedagógico, buscando interferir na gestão da escola como um todo, evidenciando a sala de aula. Prevê que os planos de aula devem ser adaptados à rotina escolar, flexíveis e refletidos nos horários coletivos de trabalho pedagógico; ao mesmo tempo, indica, também, que tais planos devem contemplar a proposta curricular e que o professor coordenador deve atuar nesta mediação, considerando que a avaliação se torne uma consequência. A proposta expõe a necessidade da construção do consenso no trabalho da gestão no interior das escolas e, também, de intervenção para a centralização das ações a serem avaliadas.

O Coordenador Pedagógico é o mediador desse discurso coletivo que fala de práticas reais. Essa é uma forma de começar a construir uma equipe para desenvolver os conteúdos e métodos propostos e, consequentemente, a avaliação, em cada disciplina, série e classe, de acordo com os planos previstos na Proposta Pedagógica da escola e na Proposta Curricular do Estado de São Paulo. (SÃO PAULO, 2008e, p. 6)

A subordinação do professor coordenador ao diretor evidencia o discurso ideológico e a compreensão de gestão escolar que norteia a proposta da Seduc, tal como podemos ver na "Nota necessária”, no volume 1 do Caderno:

${ }^{15} \mathrm{O}$ volume 1 do Caderno é de autoria de Zuleika de Felice Murrie conjuntamente com Lino de Macedo e Maria Eliza Fini. Os volumes 2 e 3, de autoria de Zuleika de Felice Murrie, foram publicados no período em que Maria Helena Castro esteve como secretária de educação, cargo assumido por Paulo Renato Souza, em 2009.

Educação em Revista|Belo Horizonte|v.38|e25020|2022 
O Professor Coordenador está subordinado aos diretores de sua escola. São eles que respondem, legalmente, sobre as decisões pedagógicas da escola. Qualquer projeto ou ação do Professor Coordenador precisa ter o aceite de seu Diretor, para evitar informações contraditórias ou disputas de poder. Os diretores são os responsáveis pela escola e seu grande líder. (SÃO PAULO, 2008d, p. 11 grifo nosso)

Essa orientação não fomenta a necessidade de ocorrer amplo debate entre os sujeitos da escola acerca dos assuntos de seu interesse, mas, sim, a obediência à hierarquia da estrutura administrativa do sistema e da escola. E coloca, ainda, o/a diretor/a como detentor/a de um poder ao se referir a ele/a como um "grande lider", conotação que não corresponde ao debate histórico sobre gestão democrática, no qual se pressupõe a descentralização da tomada de decisão na escola, com a participação de outros sujeitos por meio do Conselho de Escola, do grêmio estudantil, da Associação de Pais e Mestres, por exemplo. É esta compreensão, que desconsidera os pressupostos da gestão democrática da escola, que orienta os três volumes do Caderno do gestor.

Nessa perspectiva, o conteúdo do volume 2 da coleção Caderno do Gestor apresenta o que a Secretaria de Educação considera como objetivo do Saresp, que "deve ser compreendido como mais um instrumento que está a serviço da escola” (SÃO PAULO, 2009c, p. 6), e traz uma análise dos resultados da edição do Saresp de 2008 divididas em duas partes: na Parte 1 apresenta os dados gerais da rede estadual paulista; e na Parte 2 apresenta uma análise desses resultados "em uma perspectiva [que considera] didática” (SÃO PAULO, 2009c, p. 7). ${ }^{16}$

De forma pretensamente orientadora, o volume 2 do Caderno apresenta questões que devem ser discutidas com pais, estudantes e professores sobre diferentes aspectos do Saresp: da aplicação da prova, da participação e dos resultados da prova. As análises, de cunho muitas vezes comparativo entre as escolas, permeiam os dados objetivos da prova, como a participação dos/as alunos/as e a nota alcançada pelas escolas, e não se abordam questões como a qualificação de docentes, a infraestrutura da escola e os problemas sociais do entorno, dentre outras questões como a cultura escolar e a estrutura organizacional que, de acordo com a literatura, influem na construção de uma escola de qualidade (GOMES, 2005). Além disso, por trazer questões prontas às discussões que seriam travadas com e na comunidade escolar, direciona as possibilidades de análise diferenciadas das pessoas interessadas e interfere na gestão democrática da escola.

Diante desse cenário, é possível perceber alinhamentos estratégicos quanto às políticas de produtividade, avaliação centralizada e ranqueamento, ou seja, as pautas tratadas nos volumes do Caderno do Gestor do São Paulo Faz Escola.

\section{LEGITIMANDO O CONTROLE DO TRABALHO PEDAGÓGICO}

Com o perdurar do governo do PSDB desde 1995 até o presente ano de escrita deste artigo, é possível notar dois movimentos: um caracterizado pela permanência de ações afinadas com a perspectiva da internacionalização das políticas nas quais a educação é, em grande medida, marcada e pautada pelo mercado, pela gestão para resultados; por outro, pela descontinuidade da política de Estado conferida pela $\mathrm{CF} / 88$ que, entre seus princípios, traz a gestão democrática da escola e do sistema de ensino públicos.

Essa contradição de, apesar da continuidade de governo, a descontinuidade de políticas e o fato de não atender os preceitos constitucionais de gestão democrática do ensino é importante para a

\footnotetext{
${ }^{16}$ No volume 2 do Caderno consta que foram ampliados os referenciais do Saresp 2008 em relação aos do Saresp 2007, pois o programa São Paulo Faz Escola passou a ser, junto com o Saeb, o aporte para a elaboração da matriz da avaliação externa. Ainda conforme o Caderno, com base na escala dos resultados do Saresp 2008, o desempenho geral de estudantes é considerado nos seguintes níveis: Lingua Portuguesa $-4^{\circ}$ ano do EF abaixo do básico, menor do que 150 (26,7\%); $6^{\circ}$ ano abaixo do básico, menor do que 175 (25,4\%); $8^{\circ}$ ano do EF abaixo do básico, menor do que 200 (26,1\%); $3^{\circ}$ ano do ensino médio abaixo do básico, menor do que 250 (32,9\%); Matemática - $4^{\circ}$ ano do EF abaixo do básico, menor do que 175 (39,1\%); $6^{\circ}$ ano do EF abaixo do básico, menor do que 200 (42,4\%); $8^{\circ}$ ano do EF abaixo do básico, menor do que 225 (34,5\%); $3^{\circ}$ ano do ensino médio abaixo do básico, menor do que 275 (54,3\%); Ciências da Natureza $-6^{\circ}$ ano do EF abaixo do básico, menor do que 200 (32,3\%); $8^{\circ}$ ano do EF abaixo do básico, menor do que 225 (31,7\%); $3^{\circ}$ ano do ensino médio abaixo do básico, menor do que menor do que 275 (49,8\%) (SÃO PAULO, 2009c, p. 40-51).
}

Educação em Revista|Belo Horizonte|v.38|e25020|2022 
análise da agenda da política educacional. Para Dourado (2009), a descontinuidade de políticas educacionais ocorre normalmente em função de interrupção da continuidade de políticas adotadas por governos, principalmente quando estas não são traduzidas em políticas de Estado.

A decisão do governo paulista possui proximidade com o programa No child left behind, do governo Bush nos EUA, que introduziu uma reforma escolar caracterizada por "responsabilização, testes que definiam tudo, tomada de decisão baseada em dados estatísticos, escolha escolar, escolas autônomas, privatização, desregulamentação, pagamento por mérito e competição entre as escolas" (RAVITCH, 2011, p. 37).

Esse programa fez da testagem e da responsabilização a principal estratégia de educação no país, provendo uma redução da formação dos educandos em temas do currículo, pois o referido programa "não tinha outra visão que não a de melhorar os escores dos testes em leitura e matemática. Ele produzia montanhas de dados, não cidadãos educados" (RAVITCH, 2011, p. 47).

Ao analisarmos este estreitamento na formação escolar de educandas/os, evidencia-se melhor um dos papéis históricos que têm sido cumpridos pelo currículo escolar: o de construção de homogeneidade social. Por meio de um consenso normativo e cognitivo entre sujeitos de uma sociedade, o currículo foi tratado como instrumento social que induz à padronização de uma comunidade com o pensamento único, tendo como finalidade o consenso com as políticas econômicas e sociais (APPLE, 2006).

Nessa padronização de alegada modernização de processos, foram implantados diversificados modelos que conferiram à avaliação um eixo estruturante das reformas de administração pública e de formas de governo constituídas após períodos de ditaduras, configurando-se como Estadoavaliador (AFONSO, 2013).

No atual contexto, há um deslocamento de lugares e atores de referência na educação e na comparação internacional, no qual a Organização para a Cooperação e Desenvolvimento Econômico (OCDE) é um ator de referência e o Programme for International Student Assessment (PISA) se constitui num importante instrumento de controle que serve para validar os dados de desempenho nos testes e surge como uma

[...] regulação soft bem sucedida, sendo que a atribuição de credibilidade ao PISA, por parte da acção pública afigura-se como um pré-requisito para que a politização do instrumento se concretize $[. .$. ] [e que tem] um relevo especial enquanto mecanismos de coordenação das acções, fixando os actores ao Programa, com base em relações de influência mútua, comprovando tratar-se de um instrumento de regulação multidimensional, que actua, circularmente, por diferentes espaços de regulação (global, nacional e local), envolvendo vários actores, interligados de modo multidireccional (COSTA, 2011, p. 4).

O que carece nos procedimentos de aferição de desempenho, pautados na construção de índices comparáveis em escala internacional, é a consideração da educação como um processo de atualização humano-histórica (PARO, 2012). Pois, tais políticas ditas de avaliação, aqui abordadas, agem como instrumentos de regulação e, nessa perspectiva, revelam a necessidade de que sejam criados mecanismos de controle do currículo para atingir os resultados almejados, que desconsideram a importância da participação dos sujeitos da escola na construção do processo educativo.

A partir dos referidos programas, em contraposição à política da gestão democrática como princípio constitucional, constata-se a previsão de permanência de políticas de gestão para resultados nas escolas da rede estadual de São Paulo, em consonância com a internacionalização das políticas educacionais e em curso já na primeira década do século XXI (AKKARI, 2011).

Tais programas e projetos na rede estadual paulista aprofundam um modelo de gestão adequada a moldes técnicos e padronizados que conferem aos cotidianos das escolas elementos de exterioridade, controlando suas ações em contraposição à autonomia da cultura escolar e à observação crítica das questões típicas de suas comunidades que precisam ser diagnosticadas, encaminhadas e fortalecidas coletivamente. 


\section{CONSIDERAÇÕES FINAIS}

As políticas educacionais analisadas abarcam uma variedade de ações que evidenciam a concepção de gestão para resultados de interesse da classe dominante da sociedade, em contraposição ao princípio constitucional da gestão democrática.

Elas adquirem maior identificação com o ideário neoliberal que pauta políticas educacionais de forma internacionalizada, à medida que são criadas estratégias de avaliação externa mais incisivas por meio do Idesp e, somadas a outras medidas, revela-se em suas interfaces a ênfase na centralidade da gestão do currículo, utilizando-se, para tanto, de mecanismos de controle do processo pedagógico, como Programa Ler e Escrever e sua articulação com o Programa Bolsa Escola e Universidade, a gestão do currículo com os Cadernos do Gestor e as gratificações e bonificações.

Mediante dados da pesquisa aqui apresentados, podemos afirmar que a internacionalização prevê mecanismos de controle incorporados pelas políticas governamentais, como as dos sucessivos governos paulistas. O Idesp é um exemplo desses mecanismos que estabelece metas quantitativas associadas a bônus de remuneração em vez de aumento real aos educadores, imbricado à padronização curricular, como se nota no programa Ler e Escrever e São Paulo Faz Escola, programas formulados com arranjos público-privados. Este conjunto de ações retira a autonomia de sujeitos da escola, com impacto direto na participação ativa da comunidade escolar, pressuposto da gestão democrática do ensino público.

Nesse cenário, a deliberada ausência da gestão democrática nos documentos estaduais analisados faz-nos concluir que ela não é considerada como prioridade nas políticas educacionais, menos ainda na relação com o currículo almejado pela escola e com a propalada qualidade do ensino. Visto que a qualidade necessária ao ensino é aquela dotada do sentido de construção coletiva. Com essa perspectiva, a adoção da política de gestão do currículo definida de cima para baixo, afinada com a gestão para resultados que não garantem direitos, em grande medida invade a lacuna da gestão democrática gerada intencionalmente.

Se as escolas estaduais fossem pautadas por uma política educacional que visasse à formação de uma cidadania crítica, a avaliação e o currículo seriam tratados como meios que servem ao processo de formação, à construção da autonomia, da consciência dos sujeitos, ao seu desenvolvimento, de progressos e dificuldades e não ao resultado de testes ou à padronização da formação que mais se aproximam do incentivo à competição, ao pensamento único e à naturalização da meritocracia, como forma de os sujeitos se acomodarem às condições às quais se encontram submetidos.

Se a melhoria da qualidade do ensino é reiteradamente conclamada nos programas da Seduc, a comunidade não aparece como prioritária para elaborar essas pretensas melhorias. Ao contrário, revelase o caráter autoritário das "inovações" da gestão para resultados, cujo nome fantasia Gestão do Currículo é eixo estruturante para se introduzirem metas quantitativas, centralização do currículo e controle do trabalho pedagógico com pouca importância para a gestão democrática da escola pública.

Parece que o caminho já havia sido pavimentado para que uma ordem via Twitter fosse obedecida por ampla quantidade de escolas, quando do episódio de censura e devolução das apostilas em 2019.

Para uma educação pública condizente com a transformação qualitativa da sociedade, a comunidade deve ser integrada em espaços democráticos para elaborar e praticar estratégias coletivas com vistas a uma escola pública que contribua para superação da subalternidade. Nessa perspectiva, é a escola com seus sujeitos em ação que devem pensar, refletir e propor o seu currículo. Todo e qualquer governo deve garantir tal intento.

\section{REFERÊNCIAS}

AFONSO, Almerindo Janela. Mudanças no Estado-avaliador: comparativismo internacional e teoria da modernização revisitada. Rev. Bras. Educ., Brasília, vol.18, n.53, p.267-284, 2013.

AKKARI, Abdeljalil. Internacionalização das politicas educacionais: transformações e desafios. Petrópolis: Vozes, 2011. 
APPLE, Michael. Ideologia e Currículo. 3. ed. Porto Alegre: Artmed, 2006.

BOIM, Thiago Figueira. O que e como ensinar: Proposta Curricular, materiais didáticos e prática de ensino nas escolas públicas estaduais em São Paulo (2008-2009). 2010. Dissertação (Mestrado em Educação: História, Política, Sociedade). Pontifícia Universidade Católica de São Paulo, São Paulo, 2010.

BRASIL. Constituição da República Federativa do Brasil de 1988. Brasília, DF: Presidência da República, 5 out. 1988.

Congresso Nacional. Lei n. 9.394, de 20 de dezembro de 1996. Estabelece as diretrizes e bases da educação nacional. Brasília: Congresso Nacional, 1996.

Congresso Nacional. Lei n. 10.172, de 9 de janeiro de 2001. Aprova o Plano Nacional de Educação e dá outras providências. Brasília: Congresso Nacional, 2001.

Congresso Nacional. Lei no 13.005, de 25 de junho de 2014. Aprova o Plano Nacional de Educação e dá outras providências. Brasília: Congresso Nacional, 2014.

Decreto $n^{0}$ 6.094, de 24 de abril de 2007. Dispõe sobre a implementação do Plano de Metas Compromisso Todos pela Educação... Brasília: Congresso Nacional, 2007a.

CELLARD, André. A análise documental. In: POUPART, Jean. et al. A pesquisa qualitativa: enfoques epistemológicos e metodológicos. Petrópolis: Vozes, 2008. p. 295-316.

COSTA, Estela. O "Programme for International Student Assessment" (PISA) como instrumento de regulação das políticas educativas. 2011. 2 v. Tese (Doutorado em Administração e Política Educacional). Universidade de Lisboa, Lisboa, 2011.

DOURADO, Luiz Fernandes. Políticas e gestão: novos marcos regulatórios da educação no Brasil. São Paulo: Xamã, 2009.

GOMES, Candido Alberto. A escola de qualidade para todos: abrindo as camadas da cebola. Ensaio, v.13, n.48, jul./set. Rio de Janeiro, 2005, p. 281-306.

PARO, Vitor Henrique. Administração Escolar: introdução crítica. 17. ed. São Paulo: Cortez, 2012.

RAVITCH, Diane. Vida e morte do grande sistema escolar americano: como os testes padronizados e o modelo de mercado ameaçam a educação. Porto Alegre: Sulina, 2011.

REDE ESCOLA PÚBLICA E UNIVERSIDADE. Carta aberta às diretoras e aos diretores escolares da rede estadual de São Paulo: em defesa da gestão democrática, da escola e da liberdade no ensino. São Paulo: REPU, 2019. Disponível em: <www.repu.com.br/acao-popular-apostilas >. Acesso em 17 mai. 2020.

SÃO PAULO. Secretaria da Educação de São Paulo cria nova agenda para a Educação Pública. Diário Oficial Estado de São Paulo, v. 117, n. 157, 21 ago. 2007. São Paulo: Imprensa Oficial, 2007a.

Resolução n. 22, de 29-03-07. Dispõe sobre Grupo de Trabalho para implantação e desenvolvimento dos Programas Ler e Escrever e Bolsa Formação - Escola Pública e Universidade. São Paulo, 2007b. Disponível em $<$ http://www.educacao.sp.gov.br/lise/sislegis/detresol.asp?strAto=200703290022> Acesso em 6/8/2019.

. Decreto Estadual n. 51.627, de 01 de março de 2007. Institui o Programa Bolsa Formação - Escola Pública e Universidade. São Paulo, 2007c. Disponível em: <https://www.al.sp.gov.br/repositorio/legislacao/decreto/2007/decreto-51627-

01.03.2007.html>Acesso em: 11/12/2019.

Resolução n. 83, de 4-12-2007. Dispõe sobre a expansão do Projeto Bolsa Escola Pública e Universidade na Alfabetização. São Paulo, 2007d. Disponível em: $<$ http://www.educacao.sp.gov.br/lise/sislegis/detresol.asp?strAto=200712040083>Acesso em $3 / 8 / 2019$. 
Resolução n. 86, de 19-12-2007. Institui, para o ano de 2008, o Programa "Ler e Escrever", no Ciclo I das Escolas Estaduais de Ensino Fundamental das Diretorias de Ensino da Coordenadoria de Ensino da Região Metropolitana da Grande São Paulo. São Paulo, 2007e. Disponível em: $<$ http://www.educacao.sp.gov.br/lise/sislegis/detresol.asp?strAto=200712190086 > Acesso em 23/7/2019.

Resolução n. 88, de 19-12-2007. Dispõe sobre a função gratificada de Professor Coordenador. São Paulo, 2007f. Disponível em:<http://siau.edunet.sp.gov.br/ItemLise/arquivos/88_07.HTM > Acesso em 3/8/2019.

Resolução n. 74, de 6-11-2008. Institui o Programa de Qualidade da Escola - PQE. São Paulo, 2008a. Disponível em: $<$ http://www.educacao.sp.gov.br/lise/sislegis/detresol.asp?strAto $=200811060074>$ Acesso $\quad$ em $6 / 7 / 2019$.

Assembleia Legislativa do Estado de São Paulo. Lei Complementar n. 1.078, de 17 de dezembro de 2008. Institui Bonificação por Resultados - BR, no âmbito da Secretaria da Educação. São Paulo: Imprensa Oficial, 2008b.

. Resolução n. 76, de 7-11-2008. Dispõe sobre a implementação da Proposta Curricular do Estado de São Paulo para o Ensino Fundamental e para o Ensino Médio, nas escolas da rede estadual. São Paulo, 2008c.

Disponível

em:

$<$ http://www.educacao.sp.gov.br/lise/sislegis/detresol.asp?strAto=200811070076>Acesso

em 6/7/2019.

Secretaria de Estado da Educação. Caderno do Gestor: gestão do currículo na escola - Volume 1. São Paulo: SEE, 2008d.

Secretaria de Estado da Educação. Caderno do gestor: gestão do currículo na escola - volume 3. São Paulo: SEE, 2008e.

Secretaria de Estado da Educação. Programa de Qualidade da Escola: nota técnica. São Paulo, 2009a.

Resolução n. 97, de 18-12-2009. Dispõe sobre o Setor de Trabalho do Supervisor de Ensino. São Paulo, 2009b. Disponível em: $<$ http://www.educacao.sp.gov.br/lise/sislegis/detresol.asp?strAto=200912180097>Acesso em $7 / 8 / 2019$.

Secretaria de Estado da Educação. Caderno do gestor: gestão do currículo na escola - volume 2. São Paulo: SEE, 2009c.

Secretaria de Estado da Educação. Resolução SE n. 42/2019. Institui Grupo de Trabalho com vistas à análise e revisão dos materiais didáticos do Programa São Paulo Faz Escola. São Paulo, 2019. Disponível em: <www.educacao.sp.gov.br/lise/sislegis/detresol.asp?strAto=201909040042> Acesso em 17 mai. 2020.

\section{CONTRIBUIÇÃO DAS/DOS AUTORES/AS:}

Cileda dos Santos Sant'Anna Perrella - Coleta de dados, participação ativa na análise dos dados e revisão da escrita final.

Felipe Willian Ferreira de Alencar - Coleta de dados, participação ativa na análise dos dados e revisão da escrita final. 


\section{DECLARAÇÃO DE CONFLITO DE INTERESSE}

Os autores declaram que não há conflito de interesse com o presente artigo.

Submetido: $29 / 08 / 2020$

Aprovado: $10 / 10 / 2021$ 